Toshiyuki Nakamura MD, *

Yukio Hayashi MD, *

Kiyokazu Kagawa MD, *

Ikuto Yoshiya MD, *

Nobuaki Hirata MD,$\dagger$

Hikaru Matsuda MD $\dagger$

\section{Treatment of acute right coronary artery occlusion during anesthesia}

Purpose: Perioperative coronary artery occlusion is a potentially dangerous complication causing myocardial infarction and circulatory collapse. We report a case showing severe ST segment depression in leads II and V5 during anesthesia. Diltiazem and nifedipine, but not nitroglycerine, partially improved the ST changes which were normalized by a percutaneous cardiopulmonary system (PCPS).

Clinical Features: A $7 \mathrm{I}$-yr-old man with cerebrovascular disease was scheduled for coronary artery bypass grafting (CABG). Past medical history included myocardial infarction due to right coronary artery (RCA) occlusion. Both the femoral artery and vein were cannulated percutaneously before operation and the PCPS was prepared as a back-up system. Depression of the ST segments in leads V5 and II was observed following heparinization. Although hemodynamic stability was maintained with continuous infusion of catecholamines, the ST changes were not improved by intravenous nitroglycerine. Intravenous diltiazem followed by nasal nifedipine partially improved the ST changes. The changes were normalized after induction of PCPS. No neurological complications were observed. The postoperative coronary angiography confirmed the total occlusion of RCA.

Conclusion: Calcium channel blockers were more effective than nitroglycerine in treating perioperative ST depression. However, none of them produced complete reversal of the ischemic changes which were normalized with PCPS.

Objectif : L'occlusion périopératoire de l'artère coronaire est une complication potentiellement dangereuse et peut causer un infarctus du myocarde et un collapsus circulatoire. Nous signalons un cas qui montre un sousdécalage sévère en $\mathrm{D} \| \mathrm{I}$ et $\mathrm{V} 5$ pendant l'anesthésie. Le diltiazem et la nifédipine, mais non la nitroglycérine, ont partiellement amélioré les changements du segment ST qui ont été normalisés par un système cardiopulmonaire percutané (SCPP).

Éléments cliniques : Un homme de 7 I ans, victime d'accidents vasculaires cérébraux, devait subir un pontage aortocoronarien. Ses antécédents comprenaient un infarctus du myocarde provoqué par une occlusion de l'artère coronaire droite (ACD). On a inséré des canules percutanées dans l'artère et la veine fémorales avant l'opération et le SCPP a été préparé en qualité de système de réserve. L'abaissement des segments ST en V5 et II a été observé à la suite de l'héparinisation. Même si la stabilité hémodynamique a été maintenue avec une perfusion continue de catécholamines, les changements ST n'ont pas été améliorés par la nitroglycérine intraveineuse. Le diltiazem intraveineux, suivi de nifédipine nasale, a partiellement amélioré les changements ST. Les modifications ont été normalisées après l'entrée en fonction du SCPP. Aucune complication neurologique n'a été observée. L'angiographie coronaire postopératoire a confirmé l'occlusion totale de l'ACD.

Conclusion : Les inhibiteurs calciques ont été plus efficaces que la nitroglycérine pour traiter la dépression périopératoire du segment ST. Cependant, aucun d'eux n'a produit de renversement complet des changements ischémiques qui ont été normalisés avec le SCPP.

From the Department of Anesthesiology* and First Department of Surgery, $†$ Osaka University Faculty of Medicine, Osaka, Japan. Address correspondence to: Yukio Hayashi MD, Department of Anesthesiology (D-7), Osaka University Faculty of Medicine, 2-2, Yamada-oka, Suita, Osaka 565-0871, Japan. Phone:81-6-6879-3133; Fax:81-6-6879-3139; E-mail: yhayashi@anes.med.osaka-u.ac.jp Accepted for publication July 30, 1999. 
$\mathrm{A}$ LTHOUGH occlusion of a stenosed coronary artery during operation is rare, it is a potentially dangerous complication causing myocardial infarction and circulatory collapse. ${ }^{1,2}$ This case report describes the anesthetic management of a patient who showed intraoperative ST segment depression in leads II and V5. Diltiazem and nifedipine, but not nitroglycerine, improved the ST depression which returned to normal with a percutaneous cardiopulmonary system (PCPS).

Case Report

A 71-yr-old, $63 \mathrm{~kg}$, man was admitted as an emergency for evaluation of acute myocardial infarction. Coronary angiography one year earlier showed that the posterior descending artery (PDA) arose from the right coronary artery (RCA) and there were severe stenoses $(90 \%)$ at the left main trunk, proximal left anterior descending artery (LAD), and obtuse marginal artery, and moderate stenosis $(50 \%)$ of the distal RCA. The ECG on admission showed $0.2 \mathrm{mV}$ ST elevation in lead III and $0.3,0.2,0.3,0.05,0.3,0.7,1.0$, 1.3 and $1.1 \mathrm{mV}$ ST depression in leads I, II, aVL, aVF, V2, V3, V4, V5, V6, respectively. Coronary angiography revealed that the distal RCA was completely occluded and the PDA received collateral supply from the LAD. However, the stenosis of the left coronary artery had not increased. Percutaneous transluminal coronary angioplasty (PTCA) of the RCA resulted in successful dilatation and the ST changes improved considerably. Coronary angiography, three weeks later, showed that stenosis of the RCA had developed to a critical level $(99 \%)$, and coronary artery bypass grafting (CABG) was scheduled. Past medical history included cerebral infarction and cerebral aneurysm of the left middle cerebral artery which were treated by left superficial temporal artery-middle cerebral artery bypass and coating of the aneurysm. Before operation blood pressure was stable (100-110/58-65 $\mathrm{mmHg}$ ) and there were no neurological symptoms.

The patient received $150 \mathrm{mg}$ clonidine po, and 0.3 $\mathrm{mg}$ atropine and $10 \mathrm{mg}$ morphine, $\mathrm{im}$, two hours and one hour before anesthesia, respectively. Monitoring included ECG, pulse oximetry and direct arterial pressure via the right radial artery. Anesthesia was induced with $500 \mu \mathrm{g}$ fentanyl and $5 \mathrm{mg}$ diazepam, and muscle relaxation was provided with $10 \mathrm{mg}$ vecuronium. The lungs were mechanically ventilated to maintain $\mathrm{PaCO}_{2}$ at $40-45 \mathrm{mmHg}$. Anesthesia was maintained with fentanyl, isoflurane and propofol with oxygen $\left(\mathrm{F}_{\mathrm{I}} \mathrm{O}_{2}\right.$ 0.5$1.0)$. A pulmonary artery catheter and a central venous catheter were placed. Nitroglycerin, $0.5 \mu \mathrm{g} \cdot \mathrm{kg}^{-1} \cdot \mathrm{min}^{-1}$, diltiazem, $1.0 \mu \mathrm{g} \cdot \mathrm{kg}^{-1} \cdot \mathrm{min}^{-1}$ and nicorandil, 1.0 $\mu \mathrm{g} \cdot \mathrm{kg}^{-1} \cdot \mathrm{min}^{-1}$, were continuously infused for coronary vasodilatation. The operation scheduled was direct anastomosis of the right and left internal mammary arteries to the LAD and RCA on a beating heart via a median sternotomy. Before operation, the inflow cannula (17 Fr percutaneous cannula with Carmeda bioactive surface, Medtronic, Anaheim, CA, USA) and the outflow cannula (21 Fr percutaneous cannula with Carmeda bioactive surface, Medtronic, Anaheim, CA, USA) were inserted by the Seldinger technique into the femoral artery and vein, respectively to prepare PCPS as a back-up system. Systolic blood pressure was maintained $>100 \mathrm{mmHg}$. ST depression in lead V5 was observed following temporary reduction of systemic arterial pressure to $90 \mathrm{mmHg}$ after heparinization (Figure 1B). Although hemodynamic stability could be maintained with continuous infusion of 5 $\mu \mathrm{g} \cdot \mathrm{kg}^{-1} \cdot \mathrm{min}^{-1}$ dopamine, and $0.05-0.1 \mu \mathrm{g} \cdot \mathrm{kg}^{-1} \cdot \mathrm{min}^{-1}$ norepinephrine, the ST depression in lead V5 did not improve and lead II also showed ST depression. Nitroglycerin, $450 \mathrm{mg}$, iv, did not affect the ST changes (Figure 1C). However, $1 \mathrm{mg}$ diltiazem iv slightly improved the ST changes and nasal nifedipine $(5 \mathrm{mg})$ was added. Although these treatments partially improved the ST changes, they did not recover completely (Figures 1D, E). Thus, the inflow and outflow cannulas were connected the PCPS circuit with the centrifugal pump (Bio pump ${ }^{\circledR}$, Medtronic, Anaheim, CA, USA) and membrane oxygenator (Carmeda Maxima ${ }^{\circledR}$, Medtronic, Anaheim, CA, USA) and the PCPS was introduced. The ST changes almost normalized just after induction of PCPS (Figure 1F). The anastomoses were performed during beating of the heart as scheduled. When the PDA was incised, dark blood leaked out. Separation from PCPS was completed with the support of $7 \mu \mathrm{g} \cdot \mathrm{kg}^{-1} \cdot \mathrm{min}^{-1}$ dopamine and $0.1 \mu \mathrm{g} \cdot \mathrm{kg}^{-1} \cdot \mathrm{min}^{-1}$ norepinephrine. The hemodynamic variables were stable and there were no ischemic ECG changes after PCPS. On the day after surgery, the trachea was extubated and no neurological complications were observed. Postoperative coronary angiography confirmed the total occlusion of RCA.

\section{Discussion}

This case report describes a patient undergoing CABG whose ECG ST changes indicated intraoperative occlusion of the right coronary artery. The changes were not modified by nitroglycerine, but were partially improved with diltiazem and nifedipine and were normalized with the introduction of PCPS.

The previous episode of total RCA occlusion produced severe ST depression in multiple ECG leads and was most severe in lead V5. Recanalization by PTCA 


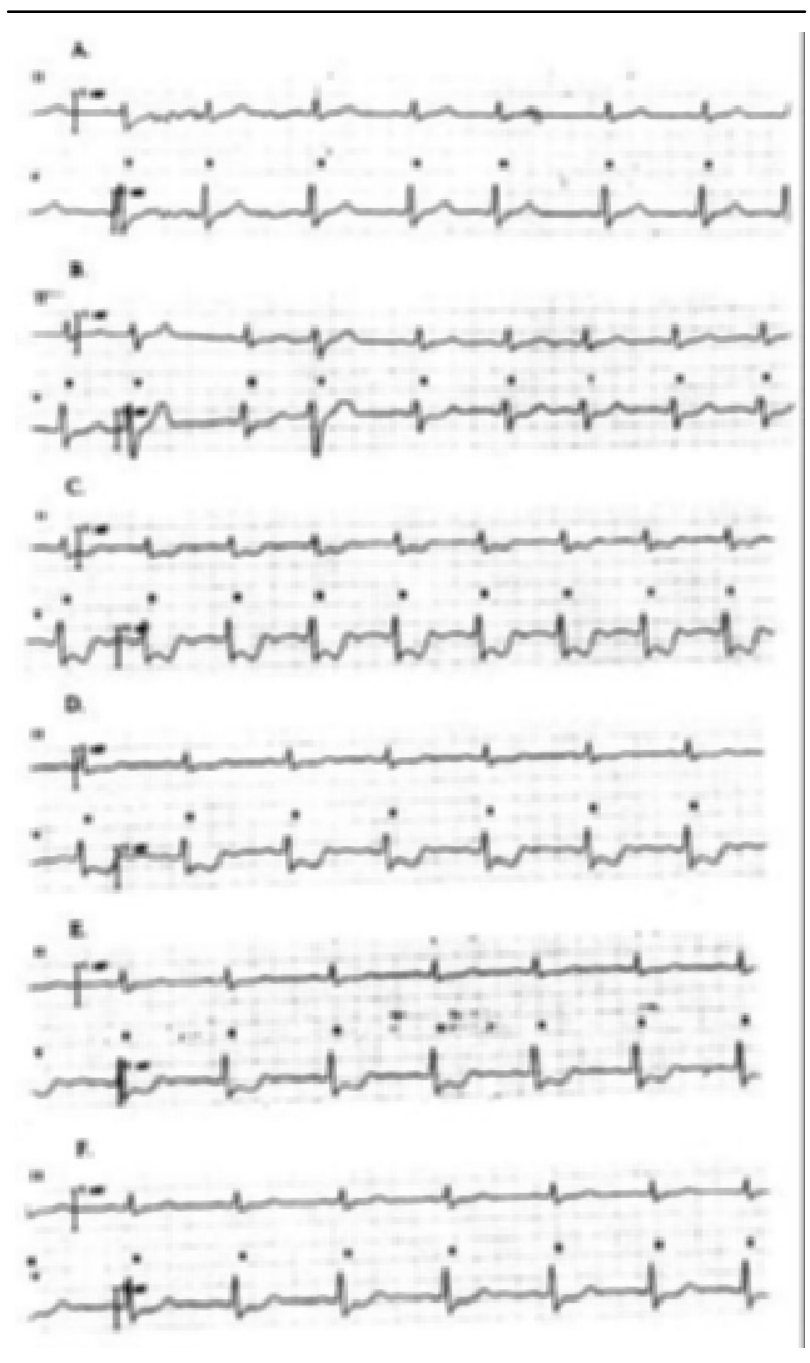

FIGURE Electrocardiogram before and after ST changes in leads II (upper) and V5 (lower trace).

A: before ST changes, Blood pressure $100 / 58 \mathrm{mmHg}$, heart rate $63 \mathrm{bpm}$.

B: The ST depression was noted in lead V5, Blood pressure $101 / 59 \mathrm{mmHg}$, heart rate $62 \mathrm{bpm}$

C: After nitroglycerine, ST depression was augmented. Blood pressure 104/52 $\mathrm{mmHg}$, heart rate $67 \mathrm{bpm}$.

D: The ST depression recovered slightly after diltiazem. Blood pressure 113/55 mmHg, heart rate $64 \mathrm{bpm}$.

E: The ST depression was partly reversed after nasal nifedipine. Blood pressure $109 / 50 \mathrm{mmHg}$, Heart rate $59 \mathrm{bpm}$

F: Introduction of PCPS. The ST change was almost normalized. Blood pressure $111 / 52 \mathrm{mmHg}$, Heart rate $63 \mathrm{bpm}$.

effectively improved these ST changes. The intraoperative ischemic ST changes in lead V5 were similar to previous episodes, suggesting recurrence of the total occlusion of RCA. Occlusion of the stenosed coronary artery may occur during anesthesia and this complica- tion may lead to serious complications, including circulatory collapse. ${ }^{3}$ In this patient, sudden hemodynamic depression did not occur and hemodynamic parameters, such as arterial blood pressure, were maintained by catecholamines until introduction of PCPS. A collateral flow from LAD to the distal site of RCA may have prevented circulatory collapse in spite of severe stenosis at the proximal LAD.

Nitrates and calcium channel blockers dilate not only the stenosed coronary artery but also the collateral artery to ameliorate myocardial ischemia. ${ }^{4,5}$ Although we gave nitroglycerin, diltiazem and nicorandil to produce coronary dilatation, the prophylactic treatment was not effective. The ST depression was not affected by injection of nitroglycerin, but was improved by intravenous diltiazem followed by nasal nifedipine (Figure 1), suggesting that calcium channel blockers may have been more effective in treating myocardial ischemia than was nitroglycerin in this patient. In addition, the ST depression was normalized by PCPS. However, dark blood appeared from the peripheral RCA during the surgery, indicating that the treatment may not have restored RCA blood supply. In fact, postoperative coronary angiography showed total occlusion of the RCA. Thus, reduction in myocardial oxygen demand more than facilitation of coronary blood flow appears to be the predominant mechanism of the antiischemic effect of calcium blockers. ${ }^{6}$

In conclusion, this case report describes the management of a patient who developed RCA occlusion during anesthesia. Calcium channel blockers, diltiazem and nifedipine, were more effective than nitroglycerin in treating the myocardial ischemia. However, they did not restore the ischemia completely which required introduction of PCPS.

\section{References}

1 Haagensen R, Steen PA. Perioperative myocardial infarction. Br J Anaesth 1988; 61: 24-37.

2 Mangano DT. Perioperative cardiac morbidity. Anesthesiology 1990; 72: 153-84.

3 Kawaguchi M, Hayashi $\Upsilon$, Kuro M, Nonogi H, Haze K. Successful treatment of acute intraoperative myocardial infarction with percutaneous transluminal coronary angioplasty under cardiopulmonary bypass. Anesthesiology 1992; 76: 472-4.

4 Kaplan JA, Dunbar RW, Jones EL. Nitroglycerin infusion during coronary-artery surgery. Anesthesiology 1976; 45: 14-21.

5 Kern MJ, Pearson A, Woodruff R, Deligonul U, Vandormael M, Labovitz A. Hemodynamic and echocardiographic assessment of the effects of diltiazem during transient occlusion of the left anterior 
descending coronary artery during percutaneous transluminal coronary angioplasty. Am J Cardiol 1989; 64: 849-55.

6 Stone PH, Antman EM, Muller JE, Braunwald E. Calcium channel blocking agents in the treatment of cardiovascular disorders. Part II: Hemodynamic effects and clinical applications. Ann Intern Med 1980; 93: 886-904. 